\title{
Burning the candle at both ends: Mitigating surgeon burnout at the training stages
}

JaBaris D. Swain, MD, MPH, ${ }^{\mathrm{a}}$ Jacqueline M. Soegaard Ballester, MD, ${ }^{\mathrm{b}}$ Jessica G. Y. Luc, MD, ${ }^{\mathrm{c}}$ and Jason J. Han, MD

\begin{abstract}
"In dealing with those who are undergoing great suffering, if you feel "burnout" setting in, if you feel demoralized and exhausted, it is best, for the sake of everyone, to withdraw and restore yourself. The point is to have a long-term perspective."
\end{abstract}

\section{-Dalai Lama}

Cardiothoracic surgery trainees face a particularly high risk of developing burnout due to long working hours, delayed career gratification, and the high stakes in patient outcomes. ${ }^{1}$ In a survey administered alongside the American Board of Surgery in-training examination in 2018, approximately $38.5 \%$ of surgical trainees reported experiencing symptoms of burnout at least weekly, with $4.5 \%$ reporting having had suicidal thoughts during the past year. ${ }^{2}$ Alarmingly, suicide has been documented as the second-leading cause of death among residents. ${ }^{2}$

As a community, we must address the notion of self-preservation and burnout early in training. What can we do to provide self-care in synchrony with our work and ultimately cope with the negative effects of emotional fatigue, physical wear, stress, and burnout such that we can continue to bring our very best to our clinical work? The following Young Surgeon's Note aims to delve into ways to mitigate burnout during cardiothoracic surgical training.

\section{RECOGNIZING BURNOUT}

Physician burnout is a complex phenomenon that refers to physical or mental deprivation often caused by overextension of oneself or a sense of inundation with excessive levels of stress. ${ }^{3}$ It has recently emerged as an alarming issue that has led to many physicians abandoning

\footnotetext{
From the Divisions of ${ }^{\mathrm{a} C}$ ardiovascular Surgery and ${ }^{\mathrm{b}}$ General Surgery, Department of Surgery, University of Pennsylvania, Philadelphia, $\mathrm{Pa}$; and ${ }^{\mathrm{c}}$ Division of Cardiovascular Surgery, Department of Surgery, University of British Columbia, Vancouver, British Columbia, Canada.

Disclosures: The authors reported no conflicts of interest.

The Journal policy requires editors and reviewers to disclose conflicts of interest and to decline handling or reviewing manuscripts for which they may have a conflict of interest. The editors and reviewers of this article have no conflicts of interest.

Received for publication April 14, 2020; revisions received June 16, 2020; accepted for publication June 21, 2020; available ahead of print July 16, 2020.

Address for reprints: Jason J. Han, MD, Division of Cardiovascular Surgery, Department of Surgery, Hospital of the University of Pennsylvania, 3400 Civic Center Blvd, Philadelphia, PA 19104 (E-mail: Jason.Han@Pennmedicine.upenn.edu).

J Thorac Cardiovasc Surg 2021;162:637-42

$0022-5223 / \$ 36.00$

Copyright (c) 2020 by The American Association for Thoracic Surgery

https://doi.org/10.1016/j.jtcvs.2020.06.122
}

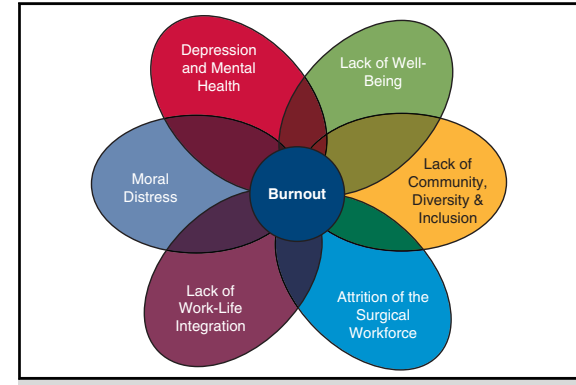

The multifaceted causes of burnout from the cardiothoracic surgical trainee perspective.

CENTRAL MESSAGE

Here, we define and offer advice to combat cardiothoracic surgical trainee burnout from the individual, institutional, and societal standpoints.

\begin{abstract}
PERSPECTIVE
Cardiothoracic surgical trainees are at great risk of developing burnout symptoms. In this article, we define and offer actionable advice from the individual, institution, and societal standpoints to combat cardiothoracic surgical trainee burnout.
\end{abstract}

See Commentaries on pages 643 and 644 .

their careers, sometimes early in their professional tenure. ${ }^{3}$ By 2025, the US Department of Health and Human Services predicts that there will be a nationwide shortage of nearly 90,000 physicians, many driven away from medicine or out of practice due to burnout. ${ }^{4}$

Early qualitative research led to the delineation of 3 dimensions of burnout-exhaustion, cynicism, and inefficacy. ${ }^{5}$ Exhaustion is described as wearing out, loss of energy, depletion, debilitation, and fatigue. Cynicism was originally termed depersonalization and is described as negative or inappropriate attitudes toward others, irritability, loss of idealism, and withdrawal. Lastly, inefficacy, which was originally termed reduced personal accomplishment, is described as reduced productivity or capability, low morale, and an inability to cope. ${ }^{6}$ Various metrics were proposed based on different assumptions about burnout, relying on the validity of the measurement items 
TABLE 1. Common workplace burnout assessment instruments

\begin{tabular}{|c|c|c|}
\hline Survey & Characteristics & Analysis \\
\hline $\begin{array}{l}\text { Maslach Burnout } \\
\text { Inventory (MBI) }\end{array}$ & $\begin{array}{l}\text { - } 22 \text {-item questionnaire } \\
\text { - Specifically designed to assess the } 3 \text { dimensions of the } \\
\text { burnout experience that had emerged from the earlier } \\
\text { qualitative research and is considered the standard tool for } \\
\text { research in this field }\end{array}$ & $\begin{array}{l}\text { - Emotional exhaustion measures feelings of being } \\
\text { emotionally overextended and exhausted by one's work } \\
\text { - Depersonalization measures an unfeeling and impersonal } \\
\text { response toward recipients of one's service, care } \\
\text { treatment, or instruction } \\
\text { - Personal accomplishment measures feelings of } \\
\text { competence and successful achievement in one's work }\end{array}$ \\
\hline Mini Z & $\begin{array}{l}\text { - Used by the AMA } \\
\text { - Was adapted from previous work performed in the } \\
\text { Physician Work life Survey (Linzer } 2000, * \text { Williams } \\
2001 \dagger \text { ) and MEMO (Linzer } 2009 \ddagger \text { ) } \\
\text { - Comprises } 10 \text { items and } 1 \text { open-ended question }\end{array}$ & $\begin{array}{l}\text { - Ten items assess satisfaction, stress, burnout, work } \\
\text { control, chaos, values alignment, teamwork, } \\
\text { documentation time pressure, excess electronic medical } \\
\text { record (EMR) use at home, and EMR proficiency } \\
\text { - Analysis of burnout drivers in the mini } \mathrm{Z} \text { with the } \\
\text { externally validated single-item burnout measure showed } \\
\text { virtually all variables associated with the burnout item at } \\
\text { the } P<.001 \text { level with } \mathrm{r} \text { values of } 0.26 \text { to } 0.46 \text { (for the } \\
\text { major burnout predictors control, EMR use, chaos, lack of } \\
\text { teamwork, lack of values alignment }\end{array}$ \\
\hline $\begin{array}{l}\text { Oldenburg Burnout } \\
\text { Inventory }\end{array}$ & $\begin{array}{l}\text { 16-item survey with positively and negatively framed } \\
\text { items that covers } 2 \text { areas: exhaustion (physical, cognitive, } \\
\text { and affective aspects) and disengagement from work } \\
\text { (negative attitudes toward work objects, work content, or } \\
\text { work in general). }\end{array}$ & $\begin{array}{l}\text { - All items are scored on a 7-point scale, ranging from (0) } \\
\text { "never" to (6) "every day" } \\
\text { - High scores on exhaustion and cynicism indicate } \\
\text { burnout } \\
\text { - Construct equivalence of the instruments used in the } \\
\text { present study for different language and educational } \\
\text { groups. }\end{array}$ \\
\hline $\begin{array}{l}\text { Copenhagen Burnout } \\
\text { Inventory }\end{array}$ & $\begin{array}{l}\text { 19-item survey with positively and negatively framed } \\
\text { items that covers } 3 \text { areas: personal (degree of physical and } \\
\text { psychological fatigue and exhaustion), work (degree of } \\
\text { physical and psychological fatigue and exhaustion related } \\
\text { to work), and client-related (or a similar term such as } \\
\text { patient, student, etc) burnout }\end{array}$ & $\begin{array}{l}\text { There are multiple questions for each subscales and } \\
\text { responses are in the form of either always, often, } \\
\text { sometimes, seldom, and never/almost never or to a very } \\
\text { high degree, to a high degree, somewhat, to a low degree, } \\
\text { and to a very low degree }\end{array}$ \\
\hline
\end{tabular}

AMA, American Medical Association. *Linzer M, Konrad TR, Douglas J, et al. Managed care, time pressure, and physician job satisfaction: results from the physician work-life study. J Gen Intern Med. 2000;15:441-50. †Williams E, Konrad T, Scheckler W, et al. Understanding physicians: Intentions to withdraw from practice: The role of job satisfaction, job stress, mental and physical health. Health Care Manage Rev. 2001;26:7-19. łLinzer M, Manwell LB, Williams ES, et al. Working conditions in primary care: physician reactions and care quality. Ann Intern Med. 2009;151:28-W9.

(Table 1). Surgeons are frequently exposed to high degrees of emotional stress. ${ }^{5}$ Burdensome workloads (eg, work hours, on-call responsibilities, research, administrative duties), the ensuing difficulty in balancing personal and professional life, feelings of losing autonomy and sense of control, and ultimately failing to find meaning in work can all contribute to burnout (Figure 1).

Burnout manifests with a wide variety of physical and cognitive symptoms, such as changes in appetite, insomnia, disengagement, hostility, broken or diminished attention span or focus, depression, anxiety, and declining physical health. In addition, burnout may lead to alcohol or substance abuse, broken relationships or divorce, or even suicide. ${ }^{3,4}$ For surgeons, mental well-being is intrinsically tied to his or her performance, and it has been reported that the majority of surgeons attributed their errors to individual factors such as an acute lapse in judgment or concentration, stress, and burnout. ${ }^{6}$
Burnout and depression are closely linked. ${ }^{5}$ Physicians are particularly at high risk for both conditions, with data suggesting that as many as one half of physicians experience burnout in some capacity, ${ }^{4}$ and $12.8 \%$ of male and $19.5 \%$ of female practicing physicians screening positive for depression, compared with about $7 \%$ of the general population. ${ }^{5}$ Some authors advocate consideration of burnout as a depressive disorder, given the overlap in symptomatology between the definitions of burnout and the diagnostic criteria for major depressive disorder. ${ }^{4}$ Others, however, caution against conflating the 2 conditions, since it risks misclassifying clinical depression as burnout. ${ }^{5}$ Given the enduring stigma associated with mental illness such as depression, substance use, and suicidality - a stigma reinforced by fear of professional sanction by medical licensing boards and other health care institutions-it might seem more "acceptable" to admit to experiencing burnout than depression. ${ }^{4}$ However, treating burnout is an inadequate 


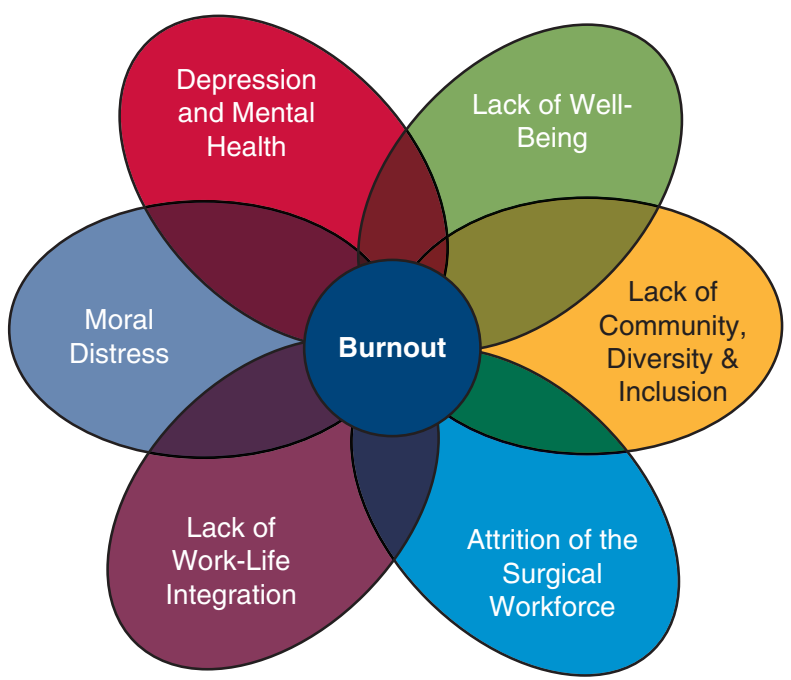

FIGURE 1. The multifaceted causes of burnout from the cardiothoracic surgical trainee perspective, including, but not limited to, the aspects of well-being, lack of community diversity and inclusion, attrition, worklife integration, moral distress, and depression and mental health.

treatment for depression. Therefore, it is important to correctly diagnose depression and to initiate appropriate pharmacologic and psychotherapeutic interventions when necessary. ${ }^{5}$

\section{BURNOUT IN CARDIOTHORACIC SURGERY TRAINEE}

Success in cardiothoracic surgery relies heavily on the mastery of fundamental technical skills as well as the development of physical prowess, intellectual agility, and moral maturity. As part of one of the longest and most arduous residency training programs, cardiothoracic surgical trainees are particularly prone to burnout due to the lack of autonomy in clinical decision-making, extended work hours, fatiguing call schedules, continuous evaluations, employment uncertainty, and the ongoing onslaught of examinations during and after training. Furthermore, they are deeply imbued with and affected by an instinctive sense of duty to patients. With this covenant comes the natural progression and the moral obligation for some trainees to develop emotional connectivity to their patients, such that a negative or unexpected outcome causes significant stress. In addition, even though the ultimate liability of a patient's outcome usually rests upon the shoulders of the attending surgeon, trainees can be and are often named in litigation, which can add a significant burden to training.

\section{MANAGEMENT OPTIONS FROM THE TRAINEE PERSPECTIVE}

For the most part, the ability to cope with work-related stressors evolves over time with experience, although frequently many faculty members still have difficulty in this regard. In an attempt to shield or protect trainees from many of these stressors as they are still developing, a variety of proactive mechanisms have been established, which include but are not limited to, Accreditation Council for Graduate Medical Education duty-hour restrictions, protected academic time for study and research, salary, and more. ${ }^{7}$ The National Academy of Medicine, in collaboration with Accreditation Council for Graduate Medical Education and Association of American Medical Colleges, convened its first action collaborative in July of 2017 titled, "Clinician Well-Being and Resilience." They defined their goals as increasing visibility of clinician stress and burnout, improving organizations' understanding of challenges to well-being, identifying evidence-based solutions, and monitoring effectiveness of solutions. In these ways, the message from leadership and the work culture of learning environments have been rendered more sensitive to the issue of burnout while lifting the stigma associated with mental health.

The following discussion describes in depth a number of strategies that cardiothoracic surgical trainees can use as they learn to acknowledge and manage their work-related stress (Table 2).

\section{Acknowledge and Manage Burnout, Develop Coping Strategies}

A third-year cardiothoracic surgery resident had their first bad outcome with causing a tear in the internal mammary artery they were assigned to harvest. The rest of the procedure goes well, but the patient ultimately received an inferior operation. The resident is afraid their attendings and colleagues will find out about this mistake and not extend future opportunities of autonomy. He or she has not heard of any other residents having caused this complication, and is cautious to reach out to anyone...

While no panacea exists to this complex, heterogeneous problem, a good starting point is to acknowledge that all residents experience some degree of burnout during their training. Currently, many trainees strive for the unrealistic notion of exceptionalism and infallibility, which tends to have a direct consequence toward burnout. Lack of early recognition leads to missed opportunities for intervention. Therefore, we need to destigmatize the concept of burnout as an end point, transitioning from a binary framework (ie, are you or are you not burned out?) to a spectrum across which most trainees find themselves at some point during their training. It is important for programs to adopt a culture of openness and transparency, being able to debrief or share vulnerabilities either with peers or trusted senior colleagues to reinforce constructive learning and to prevent isolation, and to access resources for professional psychotherapy/ 
TABLE 2. Provoking factors and strategies to overcome burnout as stratified from the individual, institutional and societal levels

\begin{tabular}{|c|c|c|}
\hline $\begin{array}{l}\text { Aspects of an } \\
\text { individual's life } \\
\text { contributing } \\
\text { to burnout }\end{array}$ & $\begin{array}{c}\text { Provoking factors } \\
\text { of burnout }\end{array}$ & $\begin{array}{c}\text { Strategies to overcome } \\
\text { burnout }\end{array}$ \\
\hline \multirow[t]{4}{*}{ Individual } & $\begin{array}{l}\text { 1. Work-life balance } \\
\text { (work hours, on-call } \\
\text { responsibilities, } \\
\text { research, } \\
\text { administrative duties) }\end{array}$ & $\begin{array}{l}\text { 1. Discover meaning in } \\
\text { work } \\
\text { 2. Be cognizant of } \\
\text { workload and reserve }\end{array}$ \\
\hline & 2. Meaning & $\begin{array}{l}\text { 1. Embody gratitude } \\
\text { 2. Practice mindfulness } \\
\text { 3. Seek counseling }\end{array}$ \\
\hline & $\begin{array}{l}\text { 3. Moral/emotional } \\
\text { distress }\end{array}$ & $\begin{array}{l}\text { 1. Establishor maintain } \\
\text { social support } \\
\text { 2. Develop } \\
\text { professionally/ } \\
\text { personally meaningful } \\
\text { outlets for distress }\end{array}$ \\
\hline & 4. Wellness & $\begin{array}{l}\text { 1. Practice self-care (eg, } \\
\text { attaining adequate } \\
\text { sleep, nutrition, fitness, } \\
\text { mindset and behavior } \\
\text { adaptability) }\end{array}$ \\
\hline \multirow[t]{4}{*}{ Institution } & 1. Toxic culture & $\begin{array}{l}\text { 1. Develop institution- } \\
\text { wide educational } \\
\text { programs about } \\
\text { physician wellness, } \\
\text { proper work culture, } \\
\text { and implicit bias } \\
\text { 2. Provide opportunities } \\
\text { for debriefing }\end{array}$ \\
\hline & $\begin{array}{l}\text { 2. Implicit bias, } \\
\text { harassment, and } \\
\text { discrimination }\end{array}$ & $\begin{array}{l}\text { 1. Enforce zero tolerance } \\
\text { policies to prevent } \\
\text { discrimination, bias, } \\
\text { and harassment } \\
\text { 2. Establish programs to } \\
\text { provide counseling }\end{array}$ \\
\hline & 3. Work-life balance & $\begin{array}{l}\text { 1. Respect duty-hour } \\
\text { restrictions }\end{array}$ \\
\hline & & $\begin{array}{l}\text { 2. Ensure access to } \\
\text { professional counseling } \\
\text { or assistance }\end{array}$ \\
\hline Society & $\begin{array}{l}\text { 1. Stigma with seeking } \\
\text { help } \\
\text { 2. Lack of community }\end{array}$ & $\begin{array}{l}\text { 1. Destigmatize burnout } \\
\text { by raising awareness } \\
\text { 1. Encourage } \\
\text { involvement in } \\
\text { professional societies, } \\
\text { organizations, support } \\
\text { groups } \\
\text { 2. Integrate social media } \\
\text { judiciously } \\
\text { 3. Provide opportunities } \\
\text { for mentorship, } \\
\text { networking, and } \\
\text { sponsorship }\end{array}$ \\
\hline
\end{tabular}

counseling for acute episodes of stress or for chronic "maintenance." Other coping mechanisms that trainees can develop include investing in outside interests, hobbies and relationships that can help sustain their outlook and personal philosophies as they go through training.

\section{Find Your Joy and Meaning and Avoid Moral Injury}

A cardiothoracic surgery resident has just finished a grueling 24-hour call shift. There were complex consultation requests and several patients who decompensated and passed away overnight. The resident provides sign out, then heads home to rest, knowing they must return to the hospital the next morning for another 24-hour shift. He or she has not had a chance to cook a proper meal at home, read, exercise, or partake in any other important hobbies over the past several months, and begins to wonder if the sacrifices are worth it.

Much emphasis has been placed on the concept of finding "balance," or "work-life integration"; however, we posit that another crucial antidote to burnout is the discovery of meaning, leading to greater personal and professional fulfillment. Meaning in work can stem from individual factors, such as recognition of work that is impactful or relevant beyond oneself. In surgical training, trainees must not lose sight of the broader impact of their work beyond their own technical and didactic education, such as the patient-lived experience. Furthermore, meaning in work can also stem from-or be eroded by-leadership. Bailey and Madden ${ }^{8}$ have described the following 7 factors as recurring themes that undermine workers' well-being, including: (1) incongruence between workers' values and those of their organization, (2) lack of recognition for hard work, (3) giving people pointless work to do, (4) treating people unfairly, (5) overriding people's better judgment, (6) disconnecting people from supportive relationships, and (7) putting people at risk for physical or emotional harm. These 7 factors provide suggestions for health care organizations and, more specifically, surgical departments, as to how to shape organizational culture and infrastructure to avoid detracting from meaning.

Finally, we can also help trainees stave off burnout by avoiding or reconciling moral distress. Moral distress can be described as an injury that affects one's identity, sense of morality, and relationship to society. For instance, moral injury occurs when we are unable to provide highquality care that meets our standards as a part of this health care system. Over time, it replaces hope with cynicism and gradually downgrades a "calling" into a "job." Institutions can help reconcile moral injury in several ways. Notably, they can help trainees learn from not only medical but also ethical complications through endeavors such as hosting ethics morbidity and mortality conferences as well as 
debriefs. Ultimately, while certain hardships are inevitable in training, systematically promoting the meaningful aspects of the profession, legitimizing the ethical dilemmas faced, and helping trainees find closure from moral injury may prove a valuable tool in combating burnout.

\section{Design Your Surgical Career for Fit and Success}

\begin{abstract}
A fourth-year cardiothoracic surgery resident is in the second year of a 2-year research fellowship. Although initially relieved to begin research due to experiencing a high degree of clinical burnout for the first 3 years, the resident is beginning to feel an insatiable urge to operate that no amount of rest, balance, or other activities have been able to fulfill. The resident is finding reassurance in their initial career choice, and feels energized to go back to the hospital.
\end{abstract}

If we consider burnout to be an extreme of work dissatisfaction, counteracting burnout should also involve each individual trainee's concerted effort to design the trajectory and structure of their surgical career for optimal "fit." Before choosing this path, trainees must thoroughly look into the various paths in surgery and decide which offers the best chance for sustainable professional productivity and satisfaction alongside personal happiness.

In the face of many external pressures, this can be a daunting and challenging task that requires ongoing introspection and self-awareness. As early as during medical school, aspiring physicians and surgeons are introduced to the concept of the "triple threat," the purported pinnacle of academic surgery. The marker of true success, we are told, is to excel by providing outstanding clinical care, participating in research to further the science of our field, and educating the next generation of medical students and trainees. Some make it a "quadruple threat" by adding participation in health care administration. However, realistically each of these "buckets" could constitute a valuable life's work; therefore, choosing the right balance between them is an important factor in preventing overextension and burnout. Identifying the ideal combination of pursuits for the individual should begin at the training stages and should be tailored to one's talents, goals, and values. This will also influence the subsequent choice of research activities, subspecialty, practice setting, and academic career "track" for those surgeons electing to practice in academic centers. Ultimately, being deliberate in choosing which areas to prioritize instead of allowing extrinsic definitions of success to drive one's career trajectory will hopefully promote one's ability to find satisfaction in the work and making meaningful contributions to the field.

4. Create an Environment of Wellness: The Importance of Diversity and Inclusion
The cardiothoracic surgery intern is 1 of 2 female residents in a group of 15 . There is 1 female attending in a division of 12 surgeons. She learns halfway throughout the year that her co-resident has been hanging out with the older residents in the program on the weekends but she doesn't know if she would be welcome at these gatherings. She occasionally catches staff in the operating room telling stories about the "last time they had a female resident." She has been doing well clinically and has tremendous academic ambitions, but has a hard time identifying a mentor with whom she can share her personal thoughts and struggles...

Diversity and inclusion are vital components of surgical training. In a survey administered with the 2018 American Board of Surgery In-Training Examination of 7409 surgical residents from 262 surgical residency programs, they demonstrated that $32 \%$ of surgical residents reported discrimination based on self-identified sex and 17\% reported racial discrimination. ${ }^{1}$ With the majority being women, victims were more likely to report symptoms of burnout (odd ratio, 2.94; $95 \%$ confidence interval, 2.58-3.36) or to have suicidal thoughts (odd ratio, 3.07, $95 \%$ confidence interval, 2.25-4.19). ${ }^{1}$ These findings were similar among cardiothoracic surgeons based on a survey by The Society of Thoracic Surgeons, which demonstrated that $39 \%$ of respondents $(83 \%$ of those who self-identify as black/African/African American) have felt unfairly treated (eg, marginalized, mistreated, harassed, excluded, bullied, not promoted or diminished) by their colleagues due to their race, ethnicity, sex, sexual orientation, religion, age, or disability status.'

Diversity and inclusion can be improved through focused educational initiatives made available to faculty, hospital staff, trainees, patients, and the general public. Tracking and maintaining transparency on diversity and advancement of minorities and providing implicit bias and leadership training are proven strategies. The creation of the Workforce of Diversity and Inclusion with The Society of Thoracic Surgeons is an important step toward achieving these goals.' Specific to trainees, growing aware of sex-specific differences in training, and supporting initiatives on equity (eg, on-site child care facilities, etc) can help meet resident-specific personal needs and professional expectations. ${ }^{10-12}$

\section{Surround Yourself With Those Who Support You}

A first-year resident enters a program full of highly ambitious but independent residents. There is little sense of community or camaraderie outside of official, departmental gatherings, and residents seem to be siloed in their respective clinical and research projects. This resident is interested in 


\section{aortic surgery but does not feel connected enough to her colleagues to reach out for advice.}

A sense of community and acceptance, both inside and outside of hospital settings, are vital to our daily interactions. ${ }^{13,14}$ These experiences provide us with a sense of place, purpose, and belonging. Membership in social clubs or professional societies, whether formally or informally, has been well documented as a deterrent to burnout.' Trainees and faculty can expand their opportunities for mentorship and inspire the next generation of surgeons. An initial step that has proven valuable in validating this cultural shift has been to organize sessions focused on mitigating burnout. Together, these efforts can help us continue to help us attract and retain the best and brightest in the field of cardiothoracic surgery. ${ }^{15}$

Social media use among surgeons has increased rapidly over the years, especially among young surgeons. This contemporary technology connects cardiothoracic surgeons around the world and fosters a larger community with which to network, mentor, collaborate and inspire. One such example is the Thoracic Surgery Social Media Network, which is a social media collaborative formed in 2015 to bring social media attention to key publications from major journals and to highlight major accomplishments in the specialty. ${ }^{16}$ By creating communities of like-minded individuals, social media has been shown to be a valuable tool to enhancing the networking and mentorship of surgeons, allowing them to find communities for social support that is not limited by time, space, or geography. ${ }^{17}$ In addition, social media allows for real-time and asynchronous international conversations, such as the ability to unite communities in campaigns on issues that matter including the \#ILookLikeASurgeon movement.

However, given the expansive reach, permanence, and lack of peer review, social media can pose ethical challenges. It is important for all users to (1) recognize the permanence of one's social media footprint, (2) extend traditional expectations of professionalism to online behavior, content, and engagement; as well as (3) be aware of and act in accordance with the social media policies set by employers and practices. Furthermore, we need to be mindful of the potentially harmful effects of social media and emotional contagion where repeated exposure to negative social media content, modelling, and reinforcement can be damaging to personal wellness. Highly edited and curated content can masquerade as "perfect" instead of conveying the many complexities and challenges of reality we face. Trainees may fall into the pitfall of exchanging many superficial encounters while growing increasingly isolated in their personal struggles. To curb this, ensure that one surrounds oneself with those who support you, limit one's exposure to negative content, and seek help when necessary.

\section{CONCLUSIONS}

Cardiothoracic surgical trainees are at great risk of developing burnout symptoms. Burnout not only impacts a surgeons' sense of professional satisfaction but can also lead to patient safety issues. A solution to burnout requires a multipronged approach. In this article, we have defined burnout from the trainee perspective and offer actionable advice from the individual, institutional, and societal standpoints to combat cardiothoracic surgical trainee burnout.

\section{References}

1. Fann JI. The seasons of a thoracic surgeon. J Thorac Cardiovasc Surg. 2017;154: 1477-86.

2. Hu YY, Ellis RJ, Hewitt DB, Yang AD, Cheung EO, Moskowitz JT, et al. Discrimination, abuse, harassment, and burnout in surgical residency training. N Engl J Med. 2019;381:1741-52.

3. Squiers JJ, Lobdell KW, Fann JI, DiMaio JM. Physician burnout: are we treating the symptoms instead of the disease? Ann Thorac Surg. 2017;104:1117-22.

4. Jha A, Lliff A, Chaoui A, Defossez S, Bombaugh M, Miller Y. A Crisis in Health Care: A Call to Action on Physician Burnout. Partnership with the Massachusetts Medical Society, Massachusetts Health and Hospital Association, Harvard T. H. Chan School of Public Health, and Harvard Global Health Institute. Available at: https://cdn1.sph.harvard.edu/wp-content/uploads/sites/21/2019/01/Physician BurnoutReport2018FINAL.pdf. Accessed April 4, 2020

5. Oquendo MA, Bernstein CA, Mayer LES. A key differential diagnosis for physicians-major depression or burnout? JAMA Psychiatry. 2019;76:1111.

6. West CP, Huschka MM, Novotny PJ, Sloan JA, Kolars JC, Habermann TM, et al. Association of perceived medical errors with resident distress and empathy: a prospective longitudinal study. J Am Med Assoc. 2006;296:1071-8.

7. Bilimoria KY, Chung JW, Hedges LV, Dahlke AR, Love R, Cohen ME, et al. National cluster-randomized trial of duty-hour flexibility in surgical training. $N$ Engl J Med. 2016:374:713-27.

8. Bailey C, Madden A. Time reclaimed: temporality and the experience of meaningful work. Work Employ Soc. 2017;31:3-18.

9. Erhunmwunsee L, Backhus LM, Godoy L, Edwards MA, Cooke DT. Report from the workforce on diversity and inclusion-the Society of Thoracic Surgeons members' bias experiences. Ann Thorac Surg. 2019;108:1287-91.

10. Corsini EM, Luc JGY, Mitchell KG, Turner NS, Vaporciyan AA, Antonoff MB Predictors of the response of operating room personnel to surgeon behaviors. Surg Today. 2019;49:927-35.

11. Meyerson SL, Sternbach JM, Zwischenberger JB, Bender EM. Resident autonomy in the operating room: expectations versus reality. Ann Thorac Surg. 2017;104:1062-8.

12. Luc JG, Antonoff MB, Vaporciyan AA, Yanagawa B. Surgeon teachers and millennial learners: bridging the generation gap. J Thorac Cardiovasc Surg. 2020 [Epub ahead of print].

13. Fann JI, Moffatt-Bruce SD, Dimaio JM, Sanchez JA. Human factors and human nature in cardiothoracic surgery. Ann Thorac Surg. 2016;101: 2059-66.

14. Kron IL. Surgical mentorship. J Thorac Cardiovasc Surg. 2011;142:489-92.

15. Kim AW, Reddy RM, Higgins RSD, Joint Council for Thoracic Surgical Education Subcommittee Best and Brightest. "Back to the future": recruiting the best and brightest into cardiothoracic surgery. J Thorac Cardiovasc Surg. 2010;140: $503-4$.

16. Luc JGY, Ouzounian M, Bender EM, Blitz A, Stamp NL, Varghese TK Jr, et al. The Thoracic Surgery Social Media Network: early experience and lessons learned. J Thorac Cardiovasc Surg. 2019;158:1127-36.

17. Luc JGY, Stamp NL, Antonoff MB. Social media as a means of networking and mentorship: role for women in cardiothoracic surgery. Semin Thorac Cardiovasc Surg. 2018;30:487-95. 